\title{
Knowledge and practice regarding prevention of cervical cancer among women attending a tertiary care centre of Tripura
}

\author{
Himadri Bhattacharjya*, Mousumi Sarkar, Nimaichand Luwang
}

Department of Community Medicine, Agartala Government Medical College, Agartala-799006, Tripura, India

Received: 20 March 2015

Accepted: 16 April 2015

\section{*Correspondence:}

Dr. Himadri Bhattacharjya,

E-mail: hbhattacharjya@ rediffmail.com,

Copyright: (C) the author(s), publisher and licensee Medip Academy. This is an open-access article distributed under the terms of the Creative Commons Attribution Non-Commercial License, which permits unrestricted non-commercial use, distribution, and reproduction in any medium, provided the original work is properly cited.

\begin{abstract}
Background: Cervical cancer is the commonest malignancy among women in developing world and is considered to be preventable. Knowledge in this regard and timely screening is crucial for prevention.

Methods: This hospital based cross-sectional study was conducted during April to May 2014, using a validated interview schedule among a representative sample of 289 women attendees of a tertiary care centre of Tripura chosen by systematic random sampling. Descriptive statistics and $\chi^{2}$ test were used to present data. $\mathrm{P}$ value $\leq 0.05$ was considered statistically significant.

Results: Cervical cancer was known as preventable by $61.9 \%$ women, $59.2 \%$ knew multiple sex partners, $42.6 \%$ knew early sexual intercourse, $72.7 \%$ knew poor personal hygiene, $26.0 \%$ knew it as a familial disease, $16.3 \%$ knew that vaccine is available for preventing cervical cancer, $41.2 \%$ knew early diagnose is possible, $59.86 \%$ knew it as a treatable disease, $31.5 \%$ knew surgery as the main mode of treatment, $15.57 \%$ have heard about PAP smear test, $10.38 \%$ underwent PAP smear test, lack of medical advice was the commonest reason for not undergoing PAP smear test and media was the main source of information for them.

Conclusions: Despite knowing cervical cancer as common among Indian women, knowledge regarding its early diagnostic methods, preventability and treatability is found to be low. Regarding the sources of information, health functionaries played poorer role than media and others. Health functionaries should gear up extensive IEC and BCC activities for making people aware and motivated regarding screening for cervical cancer to minimize preventable deaths in this community.
\end{abstract}

Keywords: Cervical cancer, Pap smear, HPV vaccine, Screening, Knowledge

\section{INTRODUCTION}

Cervical cancer is a common malignant neoplasm of the uterine cervix. It may present with vaginal bleeding but sometimes may remain asymptomatic till the disease in at advanced stage. Treatment consists of surgery in early stages and chemotherapy and radiotherapy in advanced stages of disease. ${ }^{1}$ Cervical cancer is the second leading cancer among women worldwide, and India shares a staggering one fifth of this global burden, with one out of every five women in the world suffering from cervical cancer being an Indian. ${ }^{2}$ Every year about 500000 new cases of cervical cancer are diagnosed worldwide and are responsible for about 280000 deaths. Approximately $80 \%$ of the total cases occur in developing countries. In India, cervical cancer is the most common woman-related cancer, followed by breast cancer. India contributes to about $1 / 4^{\text {th }}$ of the world's registered cervical cancer cases by having 132082 newly diagnosed cases per year and 74118 deaths. $^{3}$ Population based cancer registry program has registered 726 cases of cancer among women in Tripura during 2011. Among them 161 had carcinoma cervix followed by 107 breast cancer. ${ }^{4}$ The known primary underlying cause is the Human Papilloma Virus (HPV) especially HPV-16 and HPV-18, which is the most common sexually transmitted infection worldwide 
and it is estimated that $50 \%$ to $80 \%$ of sexually active women are infected at least once in their lifetime. Prevention of cervical cancer is achievable by preventing HPV infection and ensuring early detection and treatment which will also significantly reduce its morbidity and mortality. ${ }^{5}$ Death due to cervical cancer is now considered preventable through various strategies which subject women aged 30 years or more to periodic screening, diagnostic and therapeutic procedures which are effective. The introduction of Papanicolau (Pap) test had led to significant reduction in morbidity and mortality among women in developed countries where proportion of women screened by Pap test is high. But unfortunately its coverage is low in Asian countries. Despite existence of national guidelines, the screening coverage in India is appalling and is mainly attributed to inequality between infrastructure, resources and outsized population. Consequently, very often diagnosis of cervical cancer is based on opportunistic screening or after the onset of symptoms. ${ }^{6}$ Number of women dying from cervical cancer in Tripura is increasing day by day. Medical experts opine that a large proportion of these deaths could have been averted if proper preventive measures were adopted in time. The responsibility of prevention also lies to a great extent up on women themselves. Knowledge regarding preventability and motivation for undergoing screening is important for prevention of cervical cancer. Hence the present study was designed to find out the knowledge regarding prevention of cervical cancer, practices towards its prevention and its important determinants among women attending Gynaecology OPD of Agartala Government Medical College and Govinda Ballabh Pant Hospital, the state referral hospital of Tripura.

\section{METHODS}

This hospital based cross-sectional study was conducted during $8^{\text {th }}$ April to $7^{\text {th }}$ May 2014 among women attending outpatient department of Obstetrics and Gynaecology, Agartala Government Medical College. Minimum sample size for this study at 5\% level of significance and $10 \%$ relative error was calculated to be 304 assuming that $55.84 \%$ of the study subjects might be knowing cervical cancer as a preventable disease. ${ }^{7}$ Four patients denied participation in the study, 05 Patients were considered unfit for making any valid statement and 06 already got enrolled on the previous day, thus 15 patients were excluded and final sample size came down to 289. A predesigned, pretested, structured interview schedule was used for data collection. The interview schedule contained questions regarding education, occupation, income, marital status, age, knowledge \& practice regarding prevention of cervical cancer etc. Women's knowledge regarding cervical cancer prevention was defined as the proportion of women who knew cervical cancer as a preventable disease. Illiterate were those who did not have formal schooling. Primary educated were those who had schooling of any level between standard I to VIII. Secondary educated were those who had schooling of any level between standard VIII to XII. Graduate \& above were those who either got admitted in college, or completed general or technical graduation or above. Systematic random sampling technique was followed to choose these 289 women. Informed verbal consent for participating in this study was sought from the selected patients who were coming out after their check-up. The consenting participants were interviewed confidentially in the presence of Female Medical Social Workers spending equal for each of the respondent. Data were recorded in the interview schedule on the spot and later on entered and analysed in computer using SPSS 15 version $^{8}$ maintaining confidentiality. Descriptive statistics (like mean and standard deviation) and Chi-square test were applied and $\mathrm{P}$ value of $\leq 0.05$ was considered as significant. Prior permission from the competent authority was obtained for conducting the study.

\section{RESULTS}

Total 289 respondents got enrolled in this study and the response rate was $94.2 \%$. Mean ( \pm SD) age of the respondents was 27.86 (8.948) years and median percapita income was Rs. 1250/- per month. Majority $(60.6 \%)$ of the respondents were primary educated followed by $23.5 \%$ primary educated and both illiterate and higher educated group constituted $8 \%$ each. Majority $(83.7 \%)$ were housewives, $87.5 \%$ were Hindu by religion, and $96.5 \%$ were married. Among the participants $61.9 \%$ knew cervical cancer as a preventable disease and it is common among Indians, $6.23 \% \mathrm{knew}$ it is not and $31.83 \%$ had no idea about it. Media was the source of information for $29.41 \%$ of the women, friends and relatives for $22.49 \%$, and health workers for $16.26 \%$ whereas $31.84 \%$ women had no idea about preventability of cervical cancer. About 59.2\% women knew that having multiple sex partners and $2.4 \%$ women knew that having single sex partner is a risk factor for getting cervical cancer whereas $38.4 \%$ women had no idea about it. Regarding sexual intercourse, $42.6 \%(n=123)$ women knew that early exposure to it is a risk factor for causation of cervical cancer, $19.7 \%(n=57)$ knew later age and $37.7 \% \quad(n=109)$ women had no idea about it. Regarding personal hygiene, $72.7 \% \quad(n=210)$ women knew poor personal hygiene whereas $1.4 \% \quad(n=04)$ women knew good personal hygiene is at a risk factor for getting cervical cancer and $27.3 \%(n=75)$ women had no idea about it. Regarding heredity, $26.0 \%(n=75)$ of the study women knew cervical cancer as a familial disease, $48.7 \%(n=141)$ as not and $25.3 \%(n=73)$ women had no idea about it. Among the participants, $16.3 \% \quad(n=47)$ women knew that vaccine is available for preventing cervical cancer, $25.6 \% \quad(n=74)$ knew that there is no vaccine and $58.1 \%(n=168)$ women had no idea about the availability of any vaccine for preventing cervical cancer. About $59.86 \%(n=173)$ women knew cervical cancer as a treatable disease, $8.3 \% \quad(\mathrm{n}=24)$ as not treatable and $31.84 \%(\mathrm{n}=92)$ women had no idea about it. Regarding treatment, $31.5 \%(\mathrm{n}=91)$ women knew surgery, $20.1 \%$ $(\mathrm{n}=58)$ knew medicines and $2.4 \%(\mathrm{n}=07)$ knew radiation 
as the treatment of choice for cervical cancer; whereas $46.0 \%$ ( $n=133$ ) women had no idea about it. Regarding the possibility of diagnosing cervical cancer at an early stage $41.2 \%(n=119)$ women knew it is possible, $10.7 \%$ $(n=31)$ knew it is not, and $48.1 \%(n=139)$ women had no idea. Only $1.0 \%(n=03)$ of the study women knew biopsy as the only method for early diagnosis of cervical cancer and the rest had no idea about it. Only $15.57 \%(n=45)$ of the study women have heard about Pap smear test, $10.38 \%(n=30)$ underwent Pap smear test for the purpose of screening for cervical cancer, $9.0 \%(n=26)$ of the study women underwent Pap smear test in government hospitals and $1.38 \%(\mathrm{n}=04)$ in some private hospital and $0.3 \%(n=01)$ were found to be vaccinated against HPV for preventing cervical cancer. Reasons for not undergoing PAP smear test were not having any health problem: $4.5 \%(n=13)$, did not know where to go: $3.46 \%$ $(n=10)$, did not feel necessary: $2.42 \%(n=7)$ and not aware about the test: $89.62 \%(n=259)$. Lack of medical advice was the commonest reason for not undergoing Pap smear test irrespective of women's literacy status and only $1.09 \% \quad(n=01)$ of the higher educated women received some vaccine for preventing cervical cancer.

Table 1: Knowledge regarding frequency, preventability, early diagnosis, treatability and vaccine for cervical cancer by literacy of the study women.

\begin{tabular}{|c|c|c|c|c|}
\hline Variables & Subgroups & $\begin{array}{l}\text { Illiterate and } \\
\text { primary } \\
\text { educated } \\
\text { Number }(\%)\end{array}$ & $\begin{array}{l}\text { Secondary } \\
\text { educated, \& } \\
\text { above } \\
\text { Number }(\%)\end{array}$ & Significance \\
\hline \multirow{2}{*}{ Frequent } & Yes & $85(43.0)$ & $66(72.5)$ & \multirow{2}{*}{$\begin{array}{l}\chi^{2}=20.721 \\
P=0.000\end{array}$} \\
\hline & No & $113(57.0)$ & $25(27.5)$ & \\
\hline \multirow{2}{*}{ Preventable } & Yes & $86(43.4)$ & $67(73.6)$ & \multirow{2}{*}{$\begin{array}{l}\chi^{2}=21.616 \\
P=0.000\end{array}$} \\
\hline & No & $112(56.6)$ & $24(26.4)$ & \\
\hline \multirow{2}{*}{ Early diagnosis } & Possible & $89(45.0)$ & $61(67.0)$ & \multirow{2}{*}{$\begin{array}{l}\chi^{2}=11.311 \\
P=0.000\end{array}$} \\
\hline & Not possible & $109(55.0)$ & $30(33.0)$ & \\
\hline \multirow{2}{*}{ Treatable } & Yes & $101(51.0)$ & $63(69.2)$ & \multirow{2}{*}{$\begin{array}{l}\chi^{2}=7.707 \\
P=0.005\end{array}$} \\
\hline & No & $97(49.0)$ & $28(30.8)$ & \\
\hline \multirow{2}{*}{ Vaccine } & Available & $50(25.2)$ & $52(57.1)$ & \multirow{2}{*}{$\begin{array}{l}\chi^{2}=26.385 \\
P=0.000\end{array}$} \\
\hline & Not available & $148(74.8)$ & $39(42.9)$ & \\
\hline
\end{tabular}

Table 1 shows that significantly larger proportions of educated women were aware that cervical cancer is common among Indian, Early diagnosis of cervical cancer is possible, it is preventable, treatable and a vaccine is available for its prevention.

Table 2: Practice of undergoing Pap smear testing, by literacy, religion and occupation of the study women.

\begin{tabular}{|lllll|}
\hline \multirow{2}{*}{ Variables } & \multirow{2}{*}{$\begin{array}{l}\text { Subgroups } \\
\text { Literacy }\end{array}$} & $\begin{array}{l}\text { Undergone } \\
\text { Number }(\%)\end{array}$ & $\begin{array}{l}\text { Not undergone } \\
\text { Number (\%) }\end{array}$ & Significance \\
& Illiterate and primary & $07(3.53)$ & $191(96.47)$ & \multirow{2}{*}{$\chi^{2}=29.378$} \\
\cline { 2 - 4 } & Secondary educated and above & $23(25.27)$ & $68(74.73)$ & $\mathrm{P}=0.000$ \\
\hline \multirow{2}{*}{ Religion } & Hindu & $30(11.85)$ & $223(88.15)$ & \\
\cline { 2 - 4 } & Muslim, Christian \& others & $00(0.0)$ & $36(100.0)$ & \\
\hline \multirow{2}{*}{ Occupation } & Housewife & $22(9.09)$ & $220(90.91)$ & $\chi^{2}=1.876$ \\
\cline { 2 - 4 } & Business, service \& labourer & $08(17.02)$ & $39(82.98)$ & $\mathrm{P}=0.170$ \\
\hline
\end{tabular}

Table 2 shows that significantly higher proportion of educated women underwent $\mathrm{PAP}$ smear test $(\mathrm{P}=0.000)$ and this practice was more frequent among women engaged in the business, service \& the daily labour than those who were housewives though it was not significant $(\mathrm{P}=0.170)$.

\section{DISCUSSION}

The present study has detected the awareness regarding prevention of cervical cancer as $61.9 \%$, whereas V. Shah et al., $2012^{9}$ Found it to be $69 \%$ and Boris K et al., 2014 ${ }^{10}$ found it to be $42.4 \%$. These differences may be due to difference in the profile of the study population. In this study $59.2 \%$ subjects knew that having multiple sexual partners is a risk factor for developing carcinoma cervix whereas as per V. Shah et al., $2012^{9}$ only $11.5 \%$ nursing students had the same idea. This may be due to the fact that the student nurses were newly admitted to the course 
and had limited knowledge. In our study $42.6 \%$ of the respondents knew early exposure to sexual intercourse as a risk factor for cervical cancer whereas Sreejata Raychaudhuri et al., $2012^{6}$ have found it to be $65.6 \%$. This may be due to the differential literacy rates among the two study populations. This study has revealed that $16.3 \%$ of the study subjects were aware about availability of a vaccine for preventing carcinoma cervix similarly Sreejata Raychaudhuri et al., $2012^{6}$ also found it to be $14.5 \%$. Here only $15.57 \%$ of the study population have heard about PAP smear test whereas V. Shah et al., 2012 ${ }^{9}$ have found it to be $88.4 \%$ and Shashank Shekhar et al., $2013^{2}$ have found to be $77 \%$; this may be due to the fact that in the $2^{\text {nd }}$ case the study was conducted among nursing personnel who are likely to be more aware about cervical cancer.

Present study has revealed that $10.38 \%$ of the study population have undergone Pap smear test whereas V. Shah et al., $2012^{9}$ found it to be $8 \%$ and Shashank Shekhar et al., $2013^{2}$ found it to be $7 \%$. Low Pap smear examination rate in these two studies may be due to the fact that the nursing personals were of relatively younger in age. In this study knowledge regarding early detection of cervical cancer, Pap smear test, vaccination against cervical cancer etc. were found to be significantly related to literacy of the study subjects and it was similar with the findings of Sreejata Raychaudhuri et al., 2012. ${ }^{6}$

\section{CONCLUSION}

Despite knowing cervical cancer as common among Indian women, knowledge regarding it's early diagnostic methods, preventability and treatability is found to be low among women attending a tertiary clinic of Tripura. Though educated women had better knowledge regarding prevention of cervical cancer but practices towards early diagnosis and prevention of cervical cancer were not found to be encouraging among them. Regarding the sources of information regarding cervical cancer, health functionaries played poorer role than media and others. Hence extensive IEC and BCC activities need to be taken up by the health functionaries for making people aware and motivated regarding screening for cervical cancer in order to minimize preventable deaths in this community.

Funding: No funding sources Conflict of interest: None declared

Ethical approval: The study was approved by the institutional ethics committee of Agartala Government Medical College

\section{REFERENCES}

1. Richard N. Cervical cancer. In: Richard N, eds. Robbins Basic Pathology. 8th ed. Philadelphia: Saunders Elsevier; 2007: 718-721.

2. Shashank Shekhar, Chanderdeep Sharma, Sita Thakur, Nidhi Raina. Cervical cancer screening: knowledge, attitude and practices among nursing staff in a tertiary level teaching institution of Rural India. Asian Pac J Cancer Prev. 2013;14(6):3641-5.

3. Tharu R. Cervical cancer, 2009. Available at: http://www.medindia.net/patients. Accessed 28 June 2014.

4. PBCR India. National cancer registry programme, 2009-2011, 2011. Available at: http://www.pbcrindia.org/Pbcr_map1.htm. Accessed 14 April 2014.

5. Rohini B. Castillino, Sudha A. Raddi, Anita Dalal. Assessment of knowledge and perceived barriers to prevention of cervical cancer among women attending gynaecology OPD at KLE's Dr. Prabhakar Kore hospital and medical research center, Belgaum, Karnataka. J South Asian Feder Obstet Gynaecol. 2012;4(3):169-71.

6. Sreejata Raychaudhuri, Sukanta Mandal. Sociodemographic and behavioural risk factors for cervical cancer and knowledge, attitude and practice in rural and urban areas of North Bengal, India. Asian Pac J Cancer Prev. 2012;13:1093-6.

7. Mahendra S, Rita M, Dewesh K, Shikha M. Knowledge, attitude and practices towards cancer among urban dwellers of Jodhpur, Rajasthan. Int $\mathbf{J}$ Res Health Sci. 2014;2(1):254-62.

8. Statistical Package for the Social Sciences. SPSS for Windows. Chicago, Illinois, USA: SPSS Inc. Version 15.0; 2006. Available at: www.hist.umn.edu/ ruggles/hist5011/SPSSBriefGu ide150.pdf.

9. Shah V, Vyas S, Singh A, Shrivastava M. Awareness and knowledge of cervical cancer and its prevention among the nursing staff of a tertiary health institute in Ahmedabad, Gujarat, India. Cancer. 2012;6:270.

10. Boris K. Tchounga, Antoine Jaquet, Patrick A. Coffie, Apollinaire Horo, Catherine Sauvaget, Innocent Adoubi. Cervical cancer prevention in reproductive health Services: knowledge, attitudes and practices of midwives in Côte d'Ivoire, West Africa. BMC Health Servi Res. 2014;14:165.

DOI: 10.5455/2394-6040.ijcmph20150521

Cite this article as: Bhattacharjya $\mathrm{H}$, Sarkar M, Luwang $\mathrm{N}$. Knowledge and practice regarding prevention of cervical cancer among women attending a tertiary care centre of Tripura. Int J Community Med Public Health 2015;2:176-9. 